\title{
A model for the genetic evaluation of number of clinical mastitis cases per lactation in Czech Holstein cows
}

\author{
J. Wolf, ${ }^{1} M$ M. Wolfová, and M. Štípková \\ Institute of Animal Science, PO Box 1, CZ 10401 Prague Uhříněves, Czech Republic
}

\begin{abstract}
Cases of mastitis from 9,550 lactations of 6,242 cows were recorded on 5 farms in the Czech Republic from 1996 to 2008. The number of clinical mastitis (CM) cases per cow adjusted to a lactation length of $305 \mathrm{~d}$ was analyzed with 4 linear single-trait animal models and one 3-trait model, which also included lactation mean somatic cell score (SCS) and 305-d milk yield. Factors included in the model of choice were parity, combined effect of herd and a 2-yr calving period, calving season, permanent environmental effect of the cow, and additive genetic effect of the cow. From both the single-trait and multiple-trait models, estimated heritability of number of $\mathrm{CM}$ cases was $0.11( \pm 0.015$ for the multiple-trait model). Permanent environmental effects accounted for approximately one-third of the phenotypic variance. Heritability estimates for lactation mean SCS and 305-d milk yield were $0.17 \pm 0.019$ and $0.25 \pm 0.011$, respectively, and genetic correlations of these traits with number of CM cases were $0.80 \pm$ 0.059 and $0.34 \pm 0.079$, respectively. Genetic evaluation of the number of CM cases in Czech Holsteins could be carried out including data from all parities using a 3 -trait animal model with SCS and milk yield as additional traits.
\end{abstract}

Key words: dairy cow, clinical mastitis, genetic evaluation

\section{INTRODUCTION}

Mastitis is the most common and costly disease in dairy cattle (Halasa et al., 2007). Despite improved methods of prevention and treatment, mastitis incidence has not declined substantially in recent years. Extensive recording of health traits in the Scandinavian countries showed that genetic improvement of mastitis resistance is possible through genetic selection (Heringstad et al., 2000). In other countries, recording of clinical mastitis (CM) is not yet widely established,

Received June 2, 2009.

Accepted December 3, 2009.

${ }^{1}$ Corresponding author: wolf.jochen@vuzv.cz but several countries use udder-related type traits and SCC to select against mastitis. Although the correlation of SCC to CM is relatively high $(0.65-0.70$ in most populations; Rogers, 2002), the inclusion of CM in a selection program can substantially increase the genetic response in resistance to mastitis. Philipsson et al. (1995) reported a 20\% increase in selection efficiency for $\mathrm{CM}$ when both $\mathrm{CM}$ and $\mathrm{SCC}$ were included in a selection index. Bloemhof et al. (2009) calculated that the increase in the accuracy of the current Dutch udder health index for bulls with 100 daughters would be 3 to $8 \%$ if parity-specific CM and SCS during the first $150 \mathrm{~d}$ of lactation were included. For well-proven sires with 10,000 daughters, a $15 \%$ increase in accuracy was predicted. Heringstad et al. (2000) reported a reduction in CM incidence of $0.19 \% / \mathrm{yr}$ for cows born later than 1990 following the implementation of CM recording and selection against CM in Norway in 1978.

In initial studies in the Scandinavian countries, CM was considered as a binary trait and analyzed using a linear sire model (Heringstad et al., 1999). Further developments aimed at taking the binary nature of CM incidence into account resulted in threshold models of various kinds (univariate, multivariate, longitudinal; Heringstad et al., 2003; Chang et al. 2006). Other genetic analyses were conducted using number of $\mathrm{CM}$ cases or the number of quarters with CM during certain periods of lactation (Nash et al., 2000; Heringstad et al., 2006; Motta et al., 2006) as information sources. Day of lactation at first CM incidence was a further possible indicator trait for CM resistance (Sæbo et al., 2005; Carlén et al., 2006).

In the Czech Republic, SCS has been mainly used as an indicator trait for udder health. Furthermore, breeding values have been calculated for linear type traits including udder conformation since 1999. Registration of every CM occurrence has been obligatory on all dairy farms since 1997, but resultant records have not yet been transferred to the central database. Each treatment with antibiotics and affected quarters must be recorded on farm.

The objective of the present study was to analyze data on $\mathrm{CM}$ and other traits recorded on Czech dairy 
Table 1. Distribution of cows and lactations over herds

\begin{tabular}{llccc}
\hline Herd & Data collection period & Cows (n) & Lactations (n) $^{\text {Average herd size }}$ (cows) $^{1}$ & 1,000 \\
\hline 1 & Jan. 1, 2000 to Mar. 26, 2008 & 2,741 & 4,410 & 800 \\
2 & Dec. 23, 1998 to Aug. 23, 2007 & 1,578 & 2,225 & 200 \\
3 & Jan. 13, 1999 to Feb. 14, 2008 & 535 & 775 & 200 \\
4 & Jan. 31, 1996 to Feb. 23, 2008 & 485 & 819 & 1,000 \\
5 & Dec. 30, 2003 to Feb. 29, 2008 & 903 & 1,321 & \\
Total & & 6,242 & 9,550 & \\
\hline
\end{tabular}

${ }^{1}$ Approximate average number of cows per herd per year.

farms to determine their suitability for breeding value estimation for mastitis resistance.

\section{MATERIALS AND METHODS}

\section{Animals and Trait Definition}

Data on mastitis incidence were collected from 5 Holstein herds between 1996 and 2008. The observation length on these farms is given in Table 1. The farms were not randomly chosen from the national population, but rather were those willing to participate in the study. They were of different sizes and from distinct regions but used management, feeding, and housing systems commonly applied to dairy herds in the Czech Republic. On all farms, straw was used for bedding and cows were fed a balanced TMR and milked twice per day. All cows were treated with antibiotics at the time of drying off on farms 2 to 5 , whereas only cows with $\mathrm{CM}$ at some time during lactation plus all highproducing cows received such treatment on farm 1 . No other special mastitis control program was applied on the farms.

Records collected on farms included cow identification, date of beginning CM treatment, date of the end of $\mathrm{CM}$ (i.e., the last day that milk from a treated cow was discarded), and identification of infected quarters. Detection of CM was done by farmers on the basis of visual or perceptible signs of the udder or milk. However, a detected mastitis case was recorded only if it was treated with antibiotics prescribed by the veterinarian. Thus, CM was defined as a veterinary-treated udder disease.

The remaining data required for genetic evaluation of CM (birth date, calving date, parity, length of lactation, culling date, test-day milk yield, cumulative milk yield for lactation, and test-day SCC) together with a pedigree file were made available from the national database for progeny testing.

Only cows that started their lactation after the initiation of data collection and had a lactation length between 200 and $450 \mathrm{~d}$ were included in the analysis. Furthermore, it was required that cumulative milk yield (the calculation of which was based on at least 5 testday records) for the lactation was known. The number of cows and lactations in the analyzed dataset after data editing are shown in Table 1 . The approximate herd size was between 200 and 1,000 cows. Cows were daughters of 987 sires; the number of daughters per sire was between 1 and 114, with a median of 2 .

The trait of interest was number of $\mathrm{CM}$ cases per lactation. A new case of $\mathrm{CM}$ for the same cow was indicated when the period between the end of the previous case and the next occurrence was at least $5 \mathrm{~d}$. The frequency of cows with $\mathrm{CM}$ as a function of the day of lactation is shown for all parity classes in Figure 1. The distribution of cows over the number of CM cases per lactation is shown in Table 2. Of all cows having CM, $52 \%$ had only 1 case per lactation, $23 \%$ were ill twice, $12 \%$ had 3 cases, and $13 \%$ had more than 3 cases per lactation.

To make the number of CM cases comparable between cows and lactations, the number was preadjusted to a lactation length of $305 \mathrm{~d}$ [NCMC(305); for details see equation [3] below]. For comparison purposes, the actual (unadjusted) number of $\mathrm{CM}$ cases $\left[\operatorname{NCMC}\left(t_{l a c}\right)\right]$ for the given lactation length $t_{l a c}$ was analyzed as well. Furthermore, a second preadjusted trait was calculated $[\mathrm{NCMC}(\mathbf{3 0 5} \boldsymbol{c})]$ that was identical to $\mathrm{NCMC}(305)$ for lactations shorter than $305 \mathrm{~d}$ and the actual number of $\mathrm{CM}$ cases in the first $305 \mathrm{~d}$ for lactations with a length greater than $305 \mathrm{~d}$. In addition to these 3 trait definitions, CM was also considered as an all-or-none trait with values of 0 (no CM case) or 1 (at least $1 \mathrm{CM}$ case).

Somatic cell count was not analyzed directly but was first transformed to SCS according to the following equation:

$$
\mathrm{SCS}=\log _{2}\left(\frac{\mathrm{SCC}}{100,000}\right)+3
$$

The profile of average SCS across lactations is shown in Figure 2. 
Parity 1

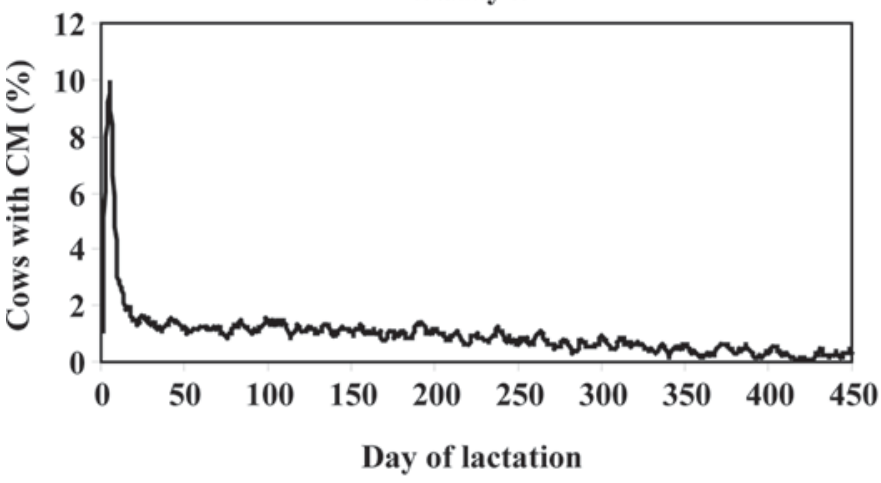

Parity 3

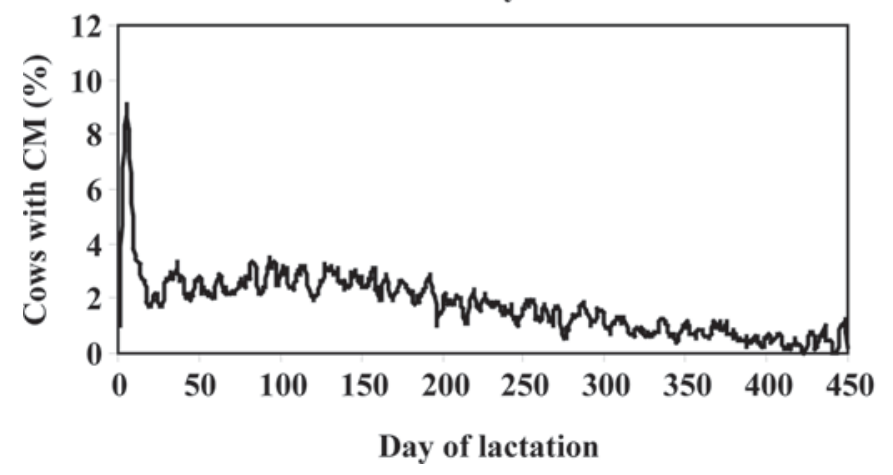

Parity 2

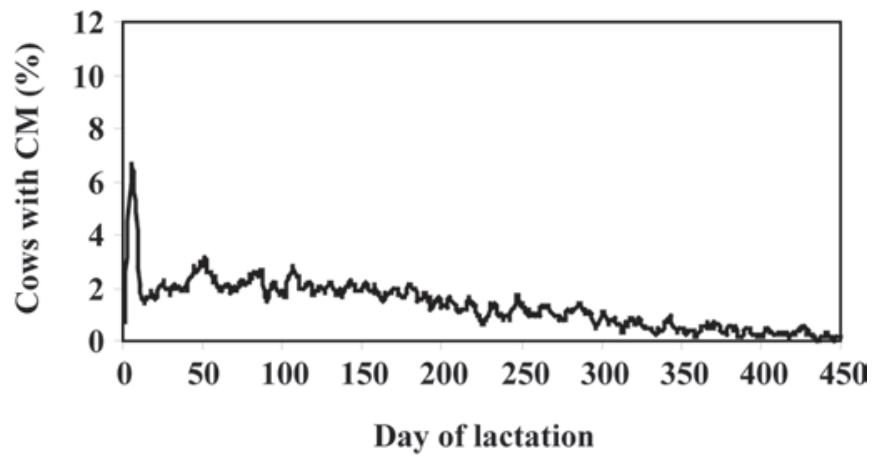

Parity 4 and higher

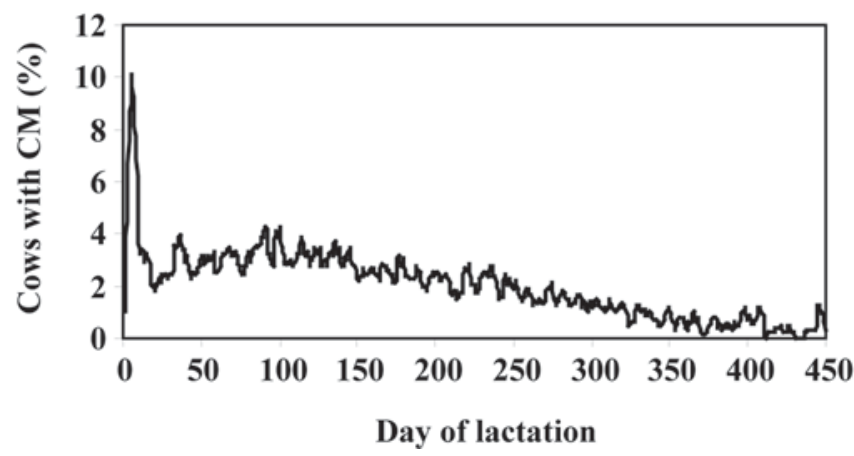

Figure 1. Frequency of cows with clinical mastitis $(\mathrm{CM})$ as a function of the day of lactation for all parity classes.

\section{Statistical Methods}

Because lactation length varied from 200 to $450 \mathrm{~d}$, preadjustment of the number of CM cases, milk yield, and SCS was considered desirable. The preadjustment was carried out within parity class. Four parity classes were defined for lactations $1,2,3$, and 4 through 10 . For adjusting the number of $\mathrm{CM}$ cases to a standard 305d lactation length, the cumulative relative frequency

Table 2. Distribution (relative frequency, \%) of the number of clinical mastitis $(\mathrm{CM})$ cases per lactation in the investigated dataset $(\mathrm{n}=$ $9,550)$

\begin{tabular}{lrrrrr}
\hline & \multicolumn{5}{c}{ Parity } \\
\cline { 2 - 6 } CM cases (n) & \multicolumn{1}{c}{1} & \multicolumn{1}{c}{2} & \multicolumn{1}{c}{3} & \multicolumn{1}{c}{$\geq 4$} & \multicolumn{1}{c}{ All } \\
\hline 0 & 54.4 & 41.7 & 31.7 & 27.7 & 42.4 \\
1 & 26.8 & 31.3 & 32.0 & 33.5 & 30.0 \\
2 & 11.0 & 12.8 & 15.9 & 16.3 & 13.2 \\
3 & 3.9 & 7.4 & 9.5 & 8.8 & 6.7 \\
4 & 2.0 & 3.4 & 4.8 & 4.5 & 3.3 \\
5 & 0.8 & 1.6 & 2.7 & 4.1 & 1.9 \\
6 & 0.5 & 0.6 & 1.2 & 2.3 & 1.0 \\
7 & 0.3 & 0.3 & 1.0 & 0.9 & 0.5 \\
8 & 0.2 & 0.5 & 0.3 & 0.3 & 0.4 \\
$\geq 9$ & 0.1 & 0.4 & 0.9 & 1.6 & 0.6 \\
\hline
\end{tabular}

of mastitis cases until lactation day $t, \mathrm{~F}(t)$, was first calculated for each parity class from the experimental data for lactation $\mathrm{d} 0$ to 450 . This function had the property that $\mathrm{F}(t)=0$ at $t=0$ and $\mathrm{F}(t)=1$ at $t=$ 450. The function $\mathrm{F}(t)$ could be well fitted by spline functions with 2 nodes at $t=150$ and $t=300$. Its general form is

$$
\begin{gathered}
\mathrm{F}(t)=m+b_{1} t+b_{2} t^{2}+\delta_{150}\left[b_{3}(t-150)\right. \\
\left.+b_{4}(t-150)^{2}\right]+\delta_{300}\left[b_{5}(t-300)+b_{6}(t-300)^{2}\right], \quad[2]
\end{gathered}
$$

where $m$ is the intercept, $b_{1}$ to $b_{6}$ are regression coefficients, and $\delta_{150}=1$ for $t \geq 150, \delta_{150}=0$ for $t<150, \delta_{300}$ $=1$ for $t \geq 300$, and $\delta_{300}=0$ for $t<300$. Intercepts and regression coefficients were specific for parity classes (Table 3).

Let $\operatorname{NCMC}\left(t_{l a c}\right)$ be the number of $\mathrm{CM}$ cases for a lactation length of $t_{l a c}$ days for a given cow. Then the adjusted number of CM cases for 305 d, NCMC(305), is

$$
\operatorname{NCMC}(305)=\frac{\mathrm{F}(305)}{\mathrm{F}\left(t_{l a c}\right)} \mathrm{NCMC}\left(t_{l a c}\right)
$$


Table 3. Values for the parameters of equation $[2]^{1}$ for the calculation of the cumulative relative frequency of clinical mastitis cases for all parity classes

\begin{tabular}{lllll}
\hline & \multicolumn{4}{c}{ Parity } \\
\cline { 2 - 5 } Parameter & \multicolumn{1}{c}{1} & \multicolumn{1}{c}{2} & \multicolumn{1}{c}{3} & \multicolumn{1}{c}{$\geq 4$} \\
\hline$m$ & 0.0617 & 0.0149 & 0.0310 & 0.0232 \\
$b_{1}$ & 0.00435 & 0.00428 & 0.00348 & 0.00405 \\
$b_{2}$ & -0.00000811 & -0.00000444 & 0 & -0.00000238 \\
$b_{3}$ & 0.000881 & 0 & -0.000414 & -0.000486 \\
$b_{4}$ & 0.00000394 & -0.00000115 & -0.00000614 & -0.00000250 \\
$b_{5}$ & 0 & 0 & 0 & -0.000279 \\
$b_{6}$ & 0 & 0.00000256 & 0.00000342 & 0.00000222 \\
\hline
\end{tabular}

${ }^{1}$ See text for equation [2].

where $\mathrm{F}(305)$ and $\mathrm{F}\left(t_{\text {lac }}\right)$ are calculated from equation [2] for $t=305$ and $t=t_{\text {lac }}$, respectively. The percentages of lactations with no CM cases, average number of CM cases, and maximum number of CM cases for each herd are summarized in Table 4.

Daily milk yield was modeled with the Wilmink function (Wilmink, 1987)

$$
z(t)=a+b t+c \mathrm{e}^{-0.05 t}
$$

Parity 1

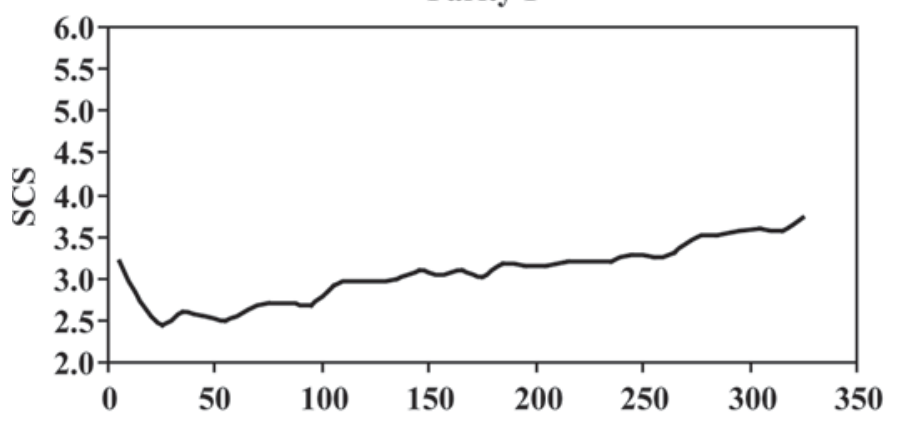

Day of lactation

Parity 3

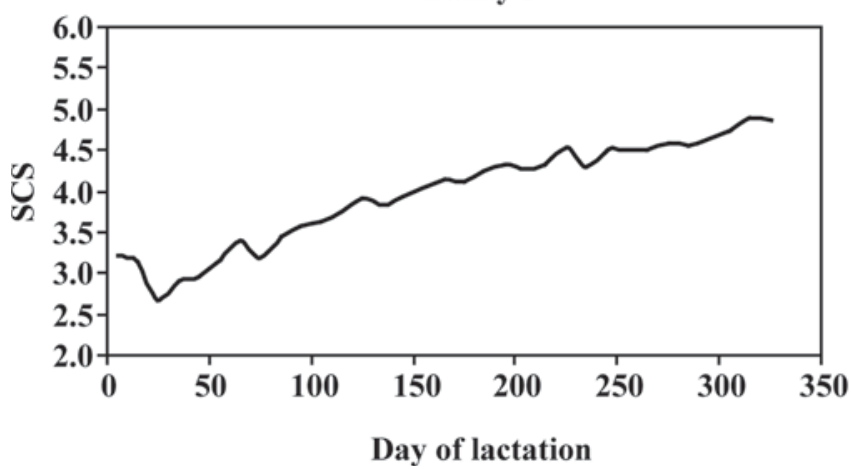

where $z(t)$ is milk yield at lactation day $t$ and $a, b$, and $c$ are coefficients that are given in Table 5 for all parity classes. The expected cumulative milk yield, $Z(t)$, from the beginning of lactation to day $t$ is then

$$
Z(t)=\int_{t^{\prime}=0}^{t^{\prime}=t} z\left(t^{\prime}\right)=a t+b \frac{t^{2}}{2}+\frac{c}{0.05}\left(\mathrm{e}^{-0.05 t}-1\right)
$$

The measured cumulative milk yield to end of lactation $t_{l a c}, \mathrm{MY}\left(t_{l a c}\right)$, for a given lactation of a given cow is then converted to the 305-d milk yield, MY(305), as follows:

$$
\mathrm{MY}(305)=\frac{Z(305)}{Z\left(t_{l a c}\right)} \mathrm{MY}\left(t_{l a c}\right)
$$

where $Z\left(t_{\text {lac }}\right)$ and $Z(305)$ are calculated according to equation [5]. The average lactation length and cumulative milk yield per lactation, both unadjusted and adjusted to a lactation length of $305 \mathrm{~d}$, are listed in Table 6 for all herds.

Lactation average SCS was calculated from test-day records (recorded in approximately monthly intervals
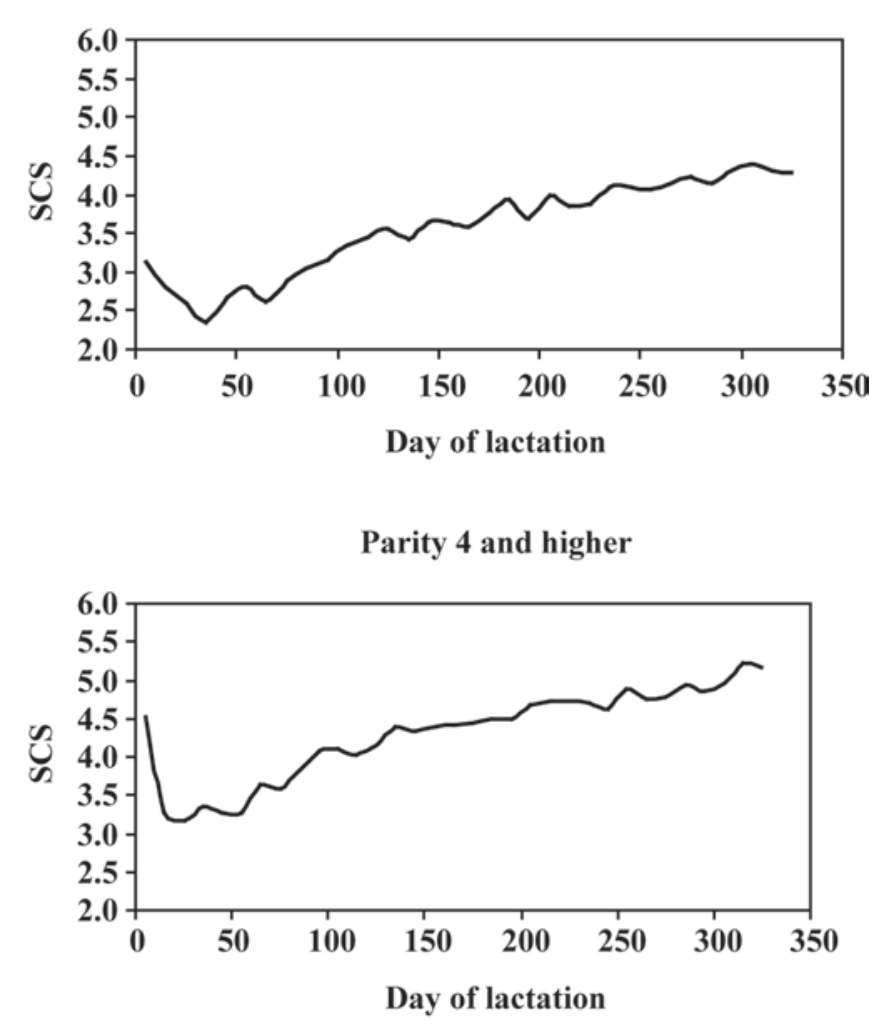

Figure 2. Somatic cell score as a function of the day of lactation for all parity classes. 
Table 4. Basic statistics for the number of mastitis cases per lactation

\begin{tabular}{|c|c|c|c|c|c|}
\hline \multirow[b]{2}{*}{ Herd } & \multirow[b]{2}{*}{$\begin{array}{l}\text { Lactations with no } \\
\text { mastitis case }(\%)\end{array}$} & \multicolumn{2}{|c|}{$\begin{array}{l}\text { Average mastitis cases/ } \\
\text { cow per lactation }(\mathrm{n})\end{array}$} & \multicolumn{2}{|c|}{$\begin{array}{l}\text { Maximum mastitis cases/ } \\
\text { cow per lactation }(\mathrm{n})\end{array}$} \\
\hline & & Unadjusted & $\begin{array}{l}\text { Adjusted to lactation } \\
\text { length of } 305 \mathrm{~d}\end{array}$ & Unadjusted & $\begin{array}{c}\text { Adjusted to lactation } \\
\text { length of } 305 \mathrm{~d}\end{array}$ \\
\hline 1 & 47.8 & 1.13 & 1.10 & 18 & 17.2 \\
\hline 2 & 22.4 & 1.63 & 1.61 & 13 & 17.0 \\
\hline 3 & 40.5 & 1.10 & 1.07 & 9 & 9.8 \\
\hline 4 & 41.6 & 1.30 & 1.27 & 13 & 12.4 \\
\hline 5 & 59.8 & 0.57 & 0.56 & 7 & 7.1 \\
\hline Total & 42.4 & 1.18 & 1.16 & 18 & 17.2 \\
\hline
\end{tabular}

with up to 10 tests/lactation) on SCC transformed to SCS according to equation [1]. In the investigated dataset, the relation between average SCS and lactation length (or day of the last SCC record) was almost linear between 200 and $330 \mathrm{~d}$; beyond $330 \mathrm{~d}$, SCC was no longer measured. Therefore, linear regression was used to adjust SCS to a lactation length of $305 \mathrm{~d}$. The coefficients for the regression equations for the individual parity classes are given in Table 7 . The average SCS corrected for a lactation length of $305 \mathrm{~d}$, SCS(305), was then calculated as

$$
\operatorname{SCS}(305)=\frac{y(305)}{y\left(t_{\text {last }}\right)} \operatorname{SCS}\left(t_{\text {last }}\right)
$$

where $\operatorname{SCS}\left(t_{\text {last }}\right)$ is the SCS averaged over all test-days when SCC is measured and $y(305)$ and $y\left(t_{\text {last }}\right)$ are the values of SCS calculated from parity-specific linear regression using coefficients given in Table 7 for 305 $\mathrm{d}$ of lactation and for the last test-day when SCC was measured, respectively. Table 8 summarizes the average values of SCS for the 5 investigated herds.

The following 4 single-trait models were used for the estimation of genetic parameters for the number of CM cases:

$$
\text { Model 1: } y_{i j m}=\text { parity }_{i}+h_{j}+p_{m}+a_{m}+e_{i j m}
$$

Model 2: $y_{i j k m}=$ parity $_{i}+h 2 y_{j}+s_{k}+p_{m}+a_{m}+e_{i j k m}$

$$
\begin{gathered}
\text { Model 3: } \begin{array}{c}
y_{i j k l m}=\text { parity }_{i}+h 2 y_{j}+s_{k}+\text { milk }_{l} \\
+p_{m}+a_{m}+e_{i j k l m}
\end{array} \\
\text { Model 4: } y_{i j k l m}=\text { parity }_{i}+h 2 y_{j}+s_{k}+b \\
\times \text { milk }_{m}+p_{m}+a_{m}+e_{i j k l m},
\end{gathered}
$$

where $y_{i j m}, y_{i j k m}$, or $y_{i j k l m}$ are number of CM cases of cow $m$ in lactation $i$, adjusted to a lactation length of 305 $\mathrm{d} ;$ parity $_{i}$ is the effect of parity class $i$ (4 levels); $h_{j}$ is the effect of herd $j$ (5 levels); $h 2 y_{j}$ is the effect of class $j$ of the combined factor of herd and a 2-year calving interval (21 levels); $s_{k}$ is the effect of calving season $k(2$ levels); inik $_{l}$ is the effect of milk yield class $l$ (2 levels); $b$ is a regression coefficient; milk $k_{m}$ is the milk yield of cow $m$ adjusted to a lactation length of $305 \mathrm{~d} ; p_{m}$ is the permanent environmental effect of cow $m$ (6,242 levels); $a_{m}$ is the additive genetic effect of cow $m$; and $e_{i j m}, e_{i j k m}$, or $e_{i j k l m}$ are the residual effects. A preliminary analysis of the effect of the calving month revealed that a statistically significant difference among seasons occurred only in comparisons of the following 2 seasons: May to October versus November to April of the following year. Preliminary analyses also showed that the formation of only 2 classes for 305-d milk yield would be sufficient: less than 6,100 L and 6,100 L and above.

For estimating the genetic correlations among number of mastitis cases, milk yield, and SCS, a 3-trait model using model 2 from equation [8] for all traits was used. The reasons for choosing model 2 are explained in the Results section below.

Restricted maximum likelihood and optimization by a quasi Newton algorithm with analytical gradients (Neumaier and Groeneveld, 1998) as implemented in the VCE 6.0 program (Groeneveld et al., 2008) were used to estimate the variances and covariances. All available pedigree information was used. The pedigree file contained 15,507 records.

Estimated genetic parameters were used in the prediction of breeding values and estimation of fixed

Table 5. Parameters $a, b$, and $c$ of the Wilmink function (equation $\left.[4]^{1}\right)$ calculated from data on test-day milk yield of the investigated dataset and used to model lactation curves for the 4 parity classes

\begin{tabular}{lccc}
\hline Parity & $a$ & $b$ & $c$ \\
\hline 1 & 32.1 & -0.0336 & -13.2 \\
2 & 40.4 & -0.0635 & -7.16 \\
3 & 41.3 & -0.0706 & -10.7 \\
$\geq 4$ & 40.3 & -0.0679 & -11.2 \\
\hline
\end{tabular}

${ }^{1}$ See text for equation [4]. 
Table 6. Summary statistics of milk yield records per herd

\begin{tabular}{|c|c|c|c|c|c|c|}
\hline \multirow[b]{3}{*}{ Herd } & & & \multicolumn{4}{|c|}{ Cumulative lactation milk yield $(\mathrm{kg})$} \\
\hline & \multicolumn{2}{|c|}{ Lactation length $(\mathrm{d})$} & \multicolumn{2}{|c|}{ Unadjusted } & \multicolumn{2}{|c|}{$\begin{array}{c}\text { Adjusted to a lactation } \\
\text { length of } 305 \mathrm{~d}\end{array}$} \\
\hline & Mean & $\mathrm{SD}$ & Mean & $\mathrm{SD}$ & Mean & $\mathrm{SD}$ \\
\hline 1 & 332 & 48.3 & 9,544 & 2,173 & 8,996 & 1,674 \\
\hline 2 & 328 & 56.9 & 8,283 & 2,233 & 7,864 & 1,735 \\
\hline 3 & 334 & 54.8 & 8,490 & 2,388 & 7,974 & 1,876 \\
\hline 4 & 332 & 52.1 & 9,700 & 2,170 & 9,185 & 1,700 \\
\hline 5 & 332 & 50.7 & 10,263 & 2,423 & 9,721 & 1,942 \\
\hline Total & 331 & 51.6 & 9,277 & 2,341 & 8,766 & 1,859 \\
\hline
\end{tabular}

effects using the same animal models as for variance component estimation. The exact solution of the equation system was calculated using the SMP solver of the PEST program (Groeneveld et al., 1990). The SAS 9.1.3 software for LINUX (SAS Institute Inc., 2002) was used for several statistical analyses (basic statistics, correlation analysis, regression analysis).

\section{RESULTS}

\section{Trait Definitions and Genetic Parameters}

When considering $\mathrm{CM}$ as an all-or-none trait, none of the 4 animal models for (co)variance estimation given in equation [8] converged. In the $\mathrm{NCMC}(305)$ analysis, estimates of variance components and standard errors were similar for all models. Residual variance was highest in model 1 , which is the least complex model with the lowest number of factors. The residual variance was equal or very similar among the remaining 3 models. Models 3 and 4 differed from model 2 by the inclusion of milk yield as a discrete factor (class variable) or a covariate, respectively. Because the residual variance was unchanged or decreased only slightly after including milk yield in the model, this factor may be ignored.

The heritability of $\mathrm{NCMC}(305)$ was 0.13 for model 1 and 0.11 for models 2 to 4 . The permanent environmental effect of the cow accounted for approximately one-third of the total phenotypic variance, and residual variance made up a little more than half the phenotypic variance in all 4 models.

Table 7. Parameters for the linear regression equations describing the dependency of the average SCS on the last test-day when SCC was measured

\begin{tabular}{lcc}
\hline Parity & Intercept & Regression coefficient \\
\hline 1 & 2.55 & 0.00157 \\
2 & 2.66 & 0.00283 \\
3 & 3.02 & 0.00291 \\
$\geq 4$ & 3.47 & 0.00260 \\
\hline
\end{tabular}

On the basis of these results, model 2 was chosen for further analyses. Variance components for traits $\operatorname{NCMC}\left(t_{l a c}\right)$ and $\operatorname{NCMC}(305 c)$ were estimated based on model 2. Table 9 summarizes all results. Calculated genetic parameters were similar for all 3 trait definitions.

Estimates of genetic parameters (proportions of the total phenotypic variance and correlations) and their standard errors from the 3-trait model analysis are shown in Table 10. Results for the number of CM cases were approximately the same as for single-trait using the same model. The precision of estimates for the 3-trait model was slightly higher than the singletrait model for CM cases (Table 9). There was a high genetic correlation (0.80) between SCS and number of $\mathrm{CM}$ cases. The genetic correlation between milk yield and number of $\mathrm{CM}$ cases was positive, with a moderate value of 0.34 . The permanent environmental effect was important for all traits, accounting for 20 to $35 \%$ of the phenotypic variance. Among traits, the number of $\mathrm{CM}$ cases showed the highest proportion of variance caused by the permanent environmental effect of the cow. There was also a high positive correlation caused by the permanent environmental effect between number of CM cases and SCS.

\section{Breeding Values and Ranking of Sires}

Pearson and Spearman rank correlation estimates between sire breeding values obtained for different trait

Table 8. Average SCS in the 5 investigated herds

\begin{tabular}{lccc}
\hline & & \multicolumn{2}{c}{ Average SCS } \\
\cline { 3 - 4 } & & & $\begin{array}{c}\text { Adjusted to a lactation } \\
\text { length of } 305 \mathrm{~d}\end{array}$ \\
\hline 1 & 3,593 & 3.89 & 3.93 \\
2 & 1,979 & 3.92 & 3.97 \\
3 & 678 & 3.70 & 3.72 \\
4 & 608 & 3.53 & 3.56 \\
5 & 1,291 & 2.77 & 2.79 \\
Total & 8,076 & 3.67 & 3.70 \\
\hline
\end{tabular}


Table 9. Variance components and their standard errors (in parentheses) estimated with model 2 of equation $[8]^{1}$ for the number of clinical mastitis $(\mathrm{CM})$ cases per lactation expressed in 3 different ways ${ }^{2}$

\begin{tabular}{lccc}
\hline Source of variation & $\mathrm{NCMC}(305)$ & $\mathrm{NCMC}\left(t_{\text {lac }}\right)$ & $\mathrm{NCMC}(305 c)$ \\
\hline Variance estimate & & & \\
$\quad$ Additive genetic & $0.238(0.039)$ & $0.252(0.037)$ & $0.233(0.039)$ \\
Permanent environment & $0.756(0.045)$ & $0.716(0.042)$ & $0.689(0.045)$ \\
$\quad$ Residual & $1.168(0.026)$ & $1.190(0.024)$ & $1.233(0.027)$ \\
Proportion of the total phenotypic variance & $0.11(0.018)$ & $0.12(0.017)$ & $0.11(0.018)$ \\
$\quad$ Additive genetic & $0.35(0.020)$ & $0.33(0.019)$ & $0.32(0.020)$ \\
Permanent environment & $0.54(0.013)$ & $0.55(0.011)$ & $0.57(0.013)$ \\
Residual & &
\end{tabular}

${ }^{1}$ See text for equation $[8]$.

${ }^{2} \mathrm{NCMC}(305)=$ number of $\mathrm{CM}$ cases per lactation preadjusted to a lactation length of $305 \mathrm{~d}$ according to equation [3]. $\mathrm{NCMC}\left(t_{l a c}\right)=$ unadjusted number of $\mathrm{CM}$ cases per lactation of length $t_{\text {lac }}$. $\mathrm{NCMC}(305 c)=$ number of $\mathrm{CM}$ cases per lactation preadjusted to a lactation length of $305 \mathrm{~d}$ for lactations shorter than $305 \mathrm{~d}$; actual (unadjusted) number of CM cases in the first $305 \mathrm{~d}$ for longer lactations.

definitions are summarized in Table 11. Model 2 (see equation [8]) was used for single-trait and multiple-trait analyses. Only sires with daughters in the investigated dataset were included in the analysis. Pearson correlations were very similar to Spearman rank correlations. Although there were relatively high correlation coefficients between the breeding values for the 3 trait definitions calculated with a single-trait model, slight changes in ranking of sires may be expected. The inclusion of 2 further traits in the model for breeding value estimation caused moderate changes in the ranking of sires for number of CM cases (correlation of approximately 0.85 between breeding values from single-trait and 3-trait model).

The range of sire breeding values predicted with single-trait model 2 was 1.9 for $\operatorname{NCMC(305),~} 1.95$ for $\operatorname{NCMC}\left(t_{l a c}\right)$, and 1.80 for $\operatorname{NCMC}(305 c)$. Thus, using the best instead of the worst sire could decrease the number of CM cases per lactation in daughters by about 1 . Prediction error variance of sire breeding values was decreased by about $5 \%$ when milk yield and SCS were added to the model. The range of breeding values was approximately $5 \%$ higher in the 3 -trait model compared with single-trait model 2 . Therefore, there is a slight advantage for the 3 -trait model.

\section{Estimates of Fixed Effects}

Parity had a clear effect on the number of CM cases. The increase in $\mathrm{CM}$ cases compared with first parity was, on average, 0.3 in the second, 0.6 in the third, and 0.9 in the fourth and greater parity class. These results were similar for all models. The difference between the effects of the best and worst herds was about $1 \mathrm{CM}$ case per lactation. The effect of season averaged over herds and years was relatively low. There were about 0.1 more CM cases per lactation in November to April than May to October. The estimates of the combined effect of herd and 2-yr interval of calving date showed a range of 1.7 (i.e., between the best and the worst class, there was a difference of $1.7 \mathrm{CM}$ cases per lactation). Differences within herds were mostly smaller than dif-

Table 10. Estimates of proportions of variance (on diagonal) and correlations between traits including their standard errors (in parentheses) for individual sources of variation, calculated from the 3 -trait model ${ }^{1}$

\begin{tabular}{|c|c|c|c|}
\hline Trait & NCMC(305) & $\mathrm{MY}(305)$ & $\operatorname{SCS}(305)$ \\
\hline \multicolumn{4}{|c|}{ Heritabilities and genetic correlation } \\
\hline $\operatorname{NCMC}(305)$ & $0.11(0.015)$ & $0.34(0.079)$ & $0.80(0.059)$ \\
\hline \multicolumn{4}{|c|}{$\begin{array}{l}\text { Proportion of variance and correlations caused by } \\
\text { the permanent environmental effect }\end{array}$} \\
\hline $\operatorname{NCMC}(305)$ & $0.34(0.018)$ & $-0.10(0.044)$ & $0.48(0.050)$ \\
\hline \multicolumn{4}{|c|}{ Proportion of variance and correlations caused by the residual effect } \\
\hline NCMC(305) & $0.54(0.011)$ & $-0.06(0.017)$ & $0.17(0.018)$ \\
\hline MY(305) & & $0.50(0.011)$ & $-0.21(0.016)$ \\
\hline $\operatorname{SCS}(305)$ & & & $0.64(0.013)$ \\
\hline
\end{tabular}

${ }^{1}$ All traits were adjusted to a lactation length of 305 d. NCMC(305) = number of clinical mastitis cases; MY(305) = 305-d milk yield; SCS(305) $=$ average SCS. 
Table 11. Correlations between breeding values estimated for different trait definitions for 987 sires having daughters in the analyzed dataset

\begin{tabular}{lcc}
\hline Pair of models $^{1}$ & Pearson correlation & Spearman's correlation \\
\hline ST-NCMC $(305)$ and ST-NCMC $\left(t_{\text {lac }}\right)$ & 0.962 & 0.950 \\
ST-NCMC $(305)$ and ST-NCMC(305c) & 0.986 & 0.979 \\
ST-NCMC $\left(t_{\text {lac }}\right)$ and ST-NCMC(305c) & 0.948 & 0.933 \\
ST-NCMC (305) and MT-NCMC(305) & 0.869 & 0.839 \\
ST-NCMC $(305 c)$ and MT-NCMC $(305 c)$ & 0.852 & 0.815 \\
\hline
\end{tabular}

${ }^{1} \mathrm{ST}=$ single-trait model; $\mathrm{NCMC}(305)=$ number of clinical mastitis $(\mathrm{CM})$ cases per lactation preadjusted to a lactation length of $305 \mathrm{~d}$ according to equation [3]; $\mathrm{NCMC}\left(t_{l a c}\right)=$ uncorrected number of $\mathrm{CM}$ cases per lactation of length $t_{\text {lac }} ; \mathrm{NCMC}(305 c)=$ number of $\mathrm{CM}$ cases per lactation preadjusted to a lactation length of $305 \mathrm{~d}$ for lactations shorter than $305 \mathrm{~d}$, actual (unadjusted) number of CM cases in the first $305 \mathrm{~d}$ for longer lactations; MT $=$ multiple-trait model.

ferences among herds. No significant time trend within herds was identified.

\section{DISCUSSION}

\section{Representativeness of the Selected Herds}

Incidence of $\mathrm{CM}$ was investigated in cows from 5 different farms. An attempt was made to include farms that well reflected the typical Czech Holstein farm in the level of milk production, reproduction, culling, and productive lifetime of cows. Cows in the selected farms represented approximately $1.4 \%$ of the Czech Holstein population. Participation in the project, however, was voluntary because farms had to be willing to provide detailed data required for the analysis. The number of farms for our investigation was restricted by our labor capacity.

The number of Czech Holstein cows involved in performance testing was about 221,000 in the years 2006 to 2007. At that time, the average size of the Czech dairy farms was approximately 240 cows, whereby $14 \%$ of the farms had more than 500 cows (J. Motyčka, Czech-Moravian Breeder's Corporation, Prague, Czech Republic, personal communication). The average productive lifetime of Holstein cows in the Czech Republic is at present 2.3 lactations. The low number of lactations is caused, among other factors, by a steady decrease in the number of cows. In the analyzed dataset, the productive lifetime was only 1.53 lactations. This number was lower than the population average because of edited data.

The average 305-d milk production of Czech Holstein cows was $8,400 \mathrm{~kg}$ and the average calving interval was $419 \mathrm{~d}$. The observed milk production in the analyzed herds was slightly higher $(8,766 \mathrm{~kg}$; Table 6$)$. There are no official statistics on the real lactation length. The total average SCS calculated from our data (3.70; Table 8 ) was very similar to the average calculated for a large dataset of Czech Holstein cows (3.77; L. Zavadilová, Institute of Animal Science, Prague Uhřiněves, Czech
Republic, personal communication). Consequently, the farms should be generally considered a representative sample of the Czech Holstein population.

\section{Trait Definition and Model}

The definition of the trait to be recorded and the selection of a suitable statistical model are 2 essential tasks in the genetic evaluation process. Trait definition should depend on the selection goal. If the objective is to discard animals with $\mathrm{CM}$, susceptibility to $\mathrm{CM}$ may be defined as an all-or-none trait. However, when taking into account the overall profitability, the number of CM cases would be a better choice (Pérez-Cabal et al., 2009).

Heritability estimates for mastitis defined as an allor-none trait have generally been low, especially from linear model analyses, where Heringstad et al. (2000) reported values from 0.02 to 0.03 . In addition to the effect of large environmental effects, low heritability of CM can be explained by the all-or-none character of the trait, which contributes to low observed variation among cows (Carlén et al., 2005, Vazquez et al., 2009). Defining CM as a binary trait can underestimate the cow susceptibility to CM because there is no distinction among cows with 1 versus multiple CM cases. Including multiple CM cases in the evaluation and handling CM in different parities as a repeatable trait can increase the variation among cows. Linear animal models for the number of CM cases also converge well. However, when CM is defined as a binary trait, the linear animal model often does not converge, so only a sire model can be used (Carlén et al., 2005).

The number of CM cases has been studied by Carlén et al. (2005), Heringstad et al. (2006), Motta et al. (2006), Pérez-Cabal et al. (2009), and Vazquez et al. (2009). In contrast to our definition, Nash et al. (2000) considered each quarter that had CM to be a separate clinical episode. Our investigation supports the findings of Carlén et al. (2005) that the animal model converges well for the number of $\mathrm{CM}$ cases per lactation. As a 
consequence, breeding values can be estimated with higher precision than with a sire model because all relationships among animals are taken into account. Our heritability estimate was approximately 0.11 , allowing for a selection against $\mathrm{CM}$ with an animal model. A similar value (0.10) was estimated by Pérez-Cabal et al. (2009) considering jointly cows of different parities and taking into account up to $5 \mathrm{CM}$ cases. Vazquez et al. (2009) reported a value of 0.07. Both estimates were from linear models. The lowest heritability estimate for the number of CM cases from a linear model (0.03) was given by Heringstad et al. (2006). The difference between our results and theirs may be explained by several factors: Heringstad et al. (2006) coded the number of CM cases greater than 2 by the number 2, they considered only first lactation records (no repeated observations for cows), and they used a sire model for variance component estimation. Furthermore, it should be taken into account that heritability estimates for categorical traits are frequency-dependent when applying linear models (Gianola, 1982). Therefore direct comparisons of estimates between studies may be sensitive to frequency differences.

Because data on the number of $\mathrm{CM}$ cases may contain an excess of zeros relative to what would be expected from some standard distribution such as Poisson sampling, Motta et al. (2006) presented a zero-inflated Poisson model for the analysis of the trait. They found that sires accounted for $7.6 \%$ of the variation in Poisson parameters of individual cows. They did not publish a heritability estimate, however, because there is no useful definition of heritability from this model.

A certain problem in the evaluation of CM susceptibility of cows is the censored character of data. Different approaches have been considered for handling this problem. When estimating genetic parameters for mastitis, some authors applied stricter data editing and included only cows that stayed in the herd for the whole period of lactation (Carlén et al., 2005, Bloemhof et al., 2009; Sørensen et al., 2009). However, this could cause a selection bias because all cows with incomplete records were excluded.

A further possibility is to include the time interval a cow was investigated (days at risk) and DIM at the starting point of investigation into the model (De Haas et al., 2002, Abdel-Azim et al., 2005). Other authors divide lactations into distinct periods in which occurrences of CM are handled as separate traits and apply multitrait sire models. In each case, only cows that stay in the herd for the entire period are included (Chang et al., 2004). This has the advantage that more data are used than when considering only complete lactations. A question connected with this approach may be how to weight the individual traits for selection. Using a censored threshold model (Heringstad et al., 2006) is an alternative approach for handling the problem of censoring.

Our philosophy was to use as much information as possible from 1 cow, including lactations of a sufficient length and, if possible, more than 1 lactation per cow. We think that this was a good way to reveal the genetic basis of the trait and estimate breeding values with maximum precision. We did not demand complete lactations, but a minimum lactation length of $200 \mathrm{~d}$ was postulated to ensure that an extrapolation on the whole lactation would be possible with reasonable precision. Furthermore, different risks of falling ill were assumed for different DIM in our method of preadjustment.

The question is whether data should actually be adjusted to a defined time interval (e.g., to the standard lactation length). In the present study, there were only small differences between estimates of genetic parameters from unadjusted and adjusted data (Table 9 ), and rank correlations between breeding values of sires predicted from unadjusted and adjusted data were relatively high (Table 11). Therefore, on the basis of our results, there is no imperative to use adjusted data. However, the adjustment of data has the advantage that trait values may be directly compared among animals. Furthermore, when changing the conditions for editing data, (e.g., when decreasing the lower limit for lactation length or using different datasets), the situation might change. Therefore, we would prefer the use of adjusted data.

A certain shortcoming of our method for preadjustment is the treatment of cows with a lactation length less than $305 \mathrm{~d}$ and no CM cases. They are expected to be free of $\mathrm{CM}$ for the standard lactation length of $305 \mathrm{~d}$. This assumption is not fully correct. We could show on our data that about $10 \%$ of the cows having no CM cases until $200 \mathrm{~d}$ had at least $1 \mathrm{CM}$ case after 200 d. However, the great majority $(90 \%)$ of cows healthy until $200 \mathrm{~d}$ were without mastitis to the end of lactation.

Differences in the type of the model seem to be of minor importance for ranking sires and the precision of EBV. Carlén et al. (2006) observed little difference in the accuracy of EBV between linear model, threshold model, and survival analysis. Results by Negussie et al. (2008) suggest no clear advantage for univariate threshold over linear models, especially when the amount of available information per sire is large. Vazquez et al. (2009) reported that predictions of sire effects from Poisson, logit, and linear models were highly correlated and that trait definition was more important than model type. Because there are no clear and unique arguments in favor of one model type over another, our decision was to use a linear model because of its computational 
advantages and the ease in modeling correlations with additional traits such as SCS and milk yield.

\section{Factors in the Model}

Similar sources of variation have been included in models for the estimation of genetic parameters and breeding value prediction in many comparable papers, independent of the model used (linear models, threshold models, survival analysis). These factors (e.g., Carlén et al., 2005; Chang et al., 2006; Heringstad et al., 2006; Negussie et al., 2006) include age at first calving, herd, calving year, season, and breed or proportion of genes from a breed. Such factors are used either separately (e. g., herd and season) or as combinations of 2 or more (e. g., herd $\times$ season classes). When treating $\mathrm{CM}$ incidence as a repeatable trait, parity and the permanent environmental effect of the cow are additional factors to be included in the model (Kadarmideen and Pryce, 2001; De Haas et al., 2002; Hinrichs et al., 2005). The effect of milk production has been considered only rarely (Hinrichs et al., 2005; Wu et al., 2008).

For the analysis of our data, parity, herd $\times 2$-yr calving period, season of calving averaged over herds and years, and the permanent environmental effect of the cow seem to be sufficient. In preliminary investigations, no systematic effect of age at calving was detected. This is in agreement with Vazquez et al. (2009), who also did not find a significant effect of age at calving on genetic parameter estimation of mastitis susceptibility defined either as an all-or-none trait or number of CM cases. The great majority of cows in our dataset were $100 \%$ Holstein, so no breed effect was necessary. The inclusion of milk yield in the model either as a class variable or covariate was of negligible effect.

In preliminary calculations comparing the herd $x$ year of calving effect with the herd $\times 2$-yr effect, we found the latter should be preferred. The effect of herd was much greater than the effect of year, so, for sufficient variability of the time effect, a longer interval should be chosen. Furthermore, the numbers of observations in the individual levels of the effect were greater for the 2-yr interval, ensuring a higher precision of the estimate of the effect.

Our results confirm the conclusion of Ouweltjes et al. (2007) that high production itself is not a major risk factor for udder health. Milk yield was highest and the number of CM cases was lowest in farm 5 , whereas the highest number of CM cases occurred on the farm with the lowest milk yield. However, there is also a question about cause and effect. The farm with lowest milk yield might actually have low yield because of mastitis.

Bloemhof et al. (2009) proposed that CM be considered as different traits in different parities. This would probably be reasonable when considering the whole breeding population in a genetic evaluation. Our dataset was relatively small and considering $\mathrm{CM}$ in individual parities as different traits would have reduced the precision of key genetic parameter estimates. Therefore, we used a repeatability model, which considerably reduced the number of genetic parameters to be estimated.

\section{Relationships Between Mastitis, SCS, and Milk Yield and Breeding Value Estimation}

The positive (unfavorable) genetic correlation between number of CM cases and milk yield, and the high positive correlation between number of $\mathrm{CM}$ cases and SCS, both observed in our investigation, are in good agreement with correlations between $\mathrm{CM}$ as binary trait and milk yield $(0.26-0.45)$ or SCS $(0.58-0.86)$ reported in the literature (Carlén et al., 2004; Hinrichs et al., 2005; Koivula et al., 2005, Negussie et al., 2006; De Haas et al., 2008).

The relationship between mastitis and milk yield is very complex and there are reciprocal effects between traits as shown by Wu et al. (2008). Their results suggest that an increased incidence of CM decreased milk yield on the following test-day, and also that the effect of test-day milk yield on CM in the next lactation period was weak. The effect of CM on milk yield depends highly on the type of mastitis pathogens, stage of lactation, and other factors (Seegers et al., 2003), as well as the interval between mastitis outbreak and test-day recording. Some farmers do not record milk yield if the cow has CM. It is also known that culling for mastitis occurs with higher frequency in cows with low milk production, so the effect of culling because of mastitis is confounded with the effect of selection against low milk yield. High-yielding cows are carefully treated when they are ill. The complex relationship among mastitis, milk yield, and culling can be the reason for the small effect of milk yield on CM in our model.

For genetic evaluation of the number of $\mathrm{CM}$ cases in Czech Holstein, the inclusion of SCS and probably also of milk yield in a multivariate analysis could be of advantage because the precision of the EBV may be increased compared with the single-trait model.

It may seem reasonable and natural that all traits are measured on the same basis; that is, records are preadjusted to a standard lactation length or to another defined time interval, or the adjustment is part of the model for breeding value estimation. The advantage of preadjustment is that the nature of the function to be used is not restricted. In the linear model for breeding value estimation, however, only functions linear in their parameters are allowed. The advantage of including the 
adjustment directly in the animal model is that all factors in the model are considered simultaneously.

For the practical application of breeding value estimation for number of CM cases in the Czech Republic, it is necessary to ensure that the records on CM available on the farms are transferred in a standardized form to the central database of the breeders' organization. If sufficient data are available, a new estimation of genetic parameters on a large dataset will be advantageous.

\section{CONCLUSIONS}

The data on CM collected on Czech dairy farms appear to be suitable for genetic evaluation of CM susceptibility. The latter may be quantitatively described by the number of CM cases per lactation, which has a heritability of approximately 0.10 and can therefore be improved by selection. A linear animal model including the permanent environmental effect of the cow is recommended for genetic evaluation of the Czech Holstein. The inclusion of SCS and milk yield as additional traits in the breeding value estimation may increase the precision of EBV for CM.

\section{ACKNOWLEDGMENTS}

Thanks are due to Petra Mrázková and Michaela Krejčová, both of Prague Uhř́něves (Czech Republic), for collecting data on CM on farms; to Marie Šimečková (Prague Uhř́něves) for her help with mathematical questions; and to the Czech-Moravian Breeder's Corporation (Prague, Czech Republic) for making data on milk performance and SCC available. Special thanks are due to W. D. Hohenboken (Corvallis, OR) for editing the English of the paper and for helpful comments. We also acknowledge the numerous constructive remarks of 2 unknown reviewers. The research was supported by the project MZE 0002701404 of the Ministry for Agriculture of the Czech Republic (Prague, Czech Republic).

\section{REFERENCES}

Abdel-Azim, G. A., A. E. Freeman, M. E. Kehrli, S. C. Kelm, J. L. Burton, A. L. Kuck, and S. Schnell. 2005. Genetic basis and risk factors for infectious and noninfectious diseases in US Holsteins. I. Estimation of genetic parameters for single diseases and general health. J. Dairy Sci. 88:1199-1207.

Bloemhof, S., G. de Jong, and Y. de Haas. 2009. Genetic parameters for clinical mastitis in the first three lactations of Dutch Holstein cattle. Vet. Microbiol. 134:165-171.

Carlén, E., U. Emanuelson, and E. Strandberg. 2006. Genetic evaluation of mastitis in dairy cattle using linear models, threshold models, and survival analysis: A simulation study. J. Dairy Sci. 89:4049-4057.

Carlén, E., M. D. Schneider, and E. Strandberg. 2005. Comparison between linear models and survival analysis for genetic evaluation of clinical mastitis in dairy cattle. J. Dairy Sci. 88:797-803.
Carlén, E., E. Strandberg, and A. Roth. 2004. Genetic parameters for clinical mastitis, somatic cell score, and production in the first three lactations of Swedish Holstein cows. J. Dairy Sci. 87:30623070 .

Chang, Y. M., D. Gianola, B. Heringstad, and G. Klemetsdal. 2004. Longitudinal analysis of clinical mastitis at different stages of lactation in Norwegian cattle. Livest. Prod. Sci. 88:251-261.

Chang, Y. M., D. Gianola, B. Heringstad, and G. Klemetsdal. 2006. A comparison between multivariate Slash, Student's t and probit threshold models for analysis of clinical mastitis in first lactation cows. J. Anim. Breed. Genet. 123:290-300.

De Haas, Y., H. W. Barkema, and R. F. Veerkamp. 2002. Genetic parameters of pathogen-specific incidence of clinical mastitis in dairy cows. Anim. Sci. 74:233-242.

De Haas, Y., W. Ouweltjes, J. ten Napel, J. J. Windig, and G. de Jong. 2008. Alternative somatic cell count traits as mastitis indicators for genetic selection. J. Dairy Sci. 91:2501-2511.

Gianola, D. 1982. Theory and analysis of threshold characters. Anim. Sci. 54:1079-1096.

Groeneveld, E., M. Kovač, and N. Mielenz. 2008. VCE User's Guide and Reference Manual. Version 6.0. Institute of Farm Animal Genetics Mariensee, Neustadt am Rübenberge, Germany.

Groeneveld, E., M. Kovac, and T. Wang. 1990. PEST, a general purpose BLUP package for multivariate prediction and estimation. Pages 488-491 in Proceedings of the 4th World Congress on Genetics Applied to Livestock Production, Edinburgh, Vol. XIII. W. G. Hill, R. Thompson, and J. A. Woolliams, ed. Organizing Committee of the 4th World Congress on Genetics Applied to Livestock Production, Edinburgh, UK.

Halasa, T., J. Huijps, O. Osteras, and H. Hogeveen. 2007. Economic effects of bovine mastitis and mastitis management: A review. Vet. Q. 29:18-31.

Heringstad, B., Y. M. Chang, I. M. Andersen-Ranberg, and D. Gianola. 2006. Genetic analysis of number of mastitis cases and number of services to conception using a censored threshold model. J. Dairy Sci. 89:4042-4048.

Heringstad, B., Y. M. Chang, D. Gianola, and G. Klemetsdal. 2003. Genetic analysis of longitudinal trajectory of clinical mastitis in first-lactation Norwegian cattle. J. Dairy Sci. 86:2676-2683.

Heringstad, B., G. Klemetsdal, and J. Ruane. 1999. Clinical mastitis in Norwegian cattle: Frequency, variance components, and genetic correlation with protein yield. J. Dairy Sci. 82:1325-1330.

Heringstad, B., G. Klemetsdal, and J. Ruane. 2000. Selection for mastitis resistance in dairy cattle: A review with focus on the situation in the Nordic countries. Livest. Prod. Sci. 64:95-106.

Hinrichs, D., E. Stamer, W. Junge, and E. Kalm. 2005. Genetic analyses of mastitis data using animal threshold models and genetic correlation with production traits. J. Dairy Sci. 88:2260-2268.

Kadarmideen, H. N., and J. E. Pryce. 2001. Genetic and economic relationships between somatic cell count and clinical mastitis and their use in selection for mastitis resistance in dairy cattle. Anim. Sci. $73: 19-28$

Koivula, M., E. A. Mäntysaari, E. Negussie, and T. Serenius. 2005. Genetic and phenotypic relationships among milk yield and somatic cell count before and after clinical mastitis. J. Dairy Sci. $88: 827-833$.

Motta, M. R., D. Gianola, Y. M. Chang, and B. Heringstad. 2006. A zero-inflated Poisson model for genetic analysis of number of mastitis cases in Norwegian Red cows. Communication no. 26-05 in Proceedings of the 8th World Congress on Genetics Applied to Livestock Production, Belo Horizonte, Brazil. CD-ROM. Organizing Committee of the 8th World Congress on Genetics Applied to Livestock Production, Belo Horizonte, Brazil.

Nash, D. L., G. W. Rogers, J. B. Cooper, G. L. Hargrove, J. F. Keown, and L. B. Hansen. 2000. Heritability of clinical mastitis incidence and relationships with sire transmitting abilities for somatic cell score, udder type traits, productive life, and protein yield. J. Dairy Sci. 83:2350-2360.

Negussie, E., M. Koivula, and E. A. Mäntysaari. 2006. Genetic parameters and single versus multi-trait evaluation of udder health traits. Acta Agric. Scand. A Anim. Sci. 56:73-82. 
Negussie, E., I. Stranden, and E. A. Mäntysaari. 2008. Genetic analysis of liability to clinical mastitis, with somatic cell score and production traits using bivariate threshold-linear and linear-linear models. Livest. Sci. 117:52-59.

Neumaier, A., and E. Groeneveld. 1998. Restricted maximum likelihood estimation of covariances in sparse linear models. Genet. Sel. Evol. 30:3-26.

Ouweltjes, W., B. Beerda, J. J. Windig, M. P. L. Calus, and R. F. Veerkamp. 2007. Effects of management and genetics on udder health and milk composition in dairy cows. J. Dairy Sci. 90:229 238.

Pérez-Cabal, M. A., G. de los Campos, A. I. Vazquez, D. Gianola, G. J. M. Rosa, K. A. Weigel, and R. Alenda. 2009. Genetic evaluation of susceptibility to clinical mastitis in Spanish Holstein cows. J Dairy Sci. 92:3472-3480.

Philipsson, J., G. Ral, and B. Berglund. 1995. Somatic cell count as a selection criterion for mastitis resistance in dairy cattle. Livest. Prod. Sci. 41:195-200.

Rogers, G. W. 2002. Aspects of milk composition, productive life and type traits in relation to mastitis and other diseases in dairy cattle. Communication no. 09-18 in Proceedings of the 7th World Congress on Genetics Applied to Livestock Production, Montpellier, France. CD-ROM. INRA, Paris, France.
Sæbo, S., T. Almoy, B. Heringstad, G. Klemetsdal, and A. H. Aastveit. 2005. Genetic evaluation of mastitis resistance using a firstpassage time model for Wiener processes for analysis of time to first treatment. J. Dairy Sci. 88:834-841.

SAS Institute Inc. 2002. SAS 9.1.3 software for LINUX. SAS Institute Inc., Cary, NC.

Seegers, H., C. Fourichon, and F. Beaudeau. 2003. Production effects related to mastitis and mastitis economics in dairy cattle herds. Vet. Res. 34:475-491.

Sørensen, L. P., P. Madsen, T. Mark, and M. S. Lund. 2009. Genetic parameters for pathogen-specific mastitis resistance in Danish Holstein cattle. Animal 3:647-656.

Vazquez, A. I., D. Gianola, D. Bates, K. A. Weigel, and B. Heringstad. 2009. Assessment of Poisson, logit, and linear models for genetic analysis of clinical mastitis in Norwegian Red cows. J. Dairy Sci. 92:739-748.

Wilmink, J. B. M. 1987. Adjustment of test-day milk, fat and protein yield for age, season and stage of lactation. Livest. Prod. Sci. $16: 335-348$.

Wu, X. L., B. Heringstad, and D. Gianola. 2008. Exploration of lagged relationships between mastitis and milk yield in dairy cows using a Bayesian structural equation Gaussian-threshold model. Genet. Sel. Evol. 40:333-357. 